\title{
MEDIA ICT DALAM PEMBELAJARAN MATEMATIKA MENGGUNAKAN POWERPOINT INTERAKTIF DAN ISPRING PRESENTER
}

\author{
Ahmad Afandi \\ IKIP PGRI JEMBER \\ Email: a_afandi41@yahoo.com
}

\begin{abstract}
The target in this extension is the Teachers of AL-Badri Vocational High School. Data collection technique is by observation and interview. Result extension obtained as follow: 1) Participants counseling obtain a lot of information related to interactive ways of teaching and not boring (in condition); 2) Improving knowledge and understanding of teachers in providing interactive learning, so learning in the classroom would be more fun.
\end{abstract}

\section{Keywords: Learning, Powerpoint, iSpring Presenter}

\begin{abstract}
Abstrak. Sasaran dalam penyuluhan ini Guru-Guru SMK AL-Badri. Teknik pengumpulan datanya yaitu dengan Observasi dan Wawancara. Hasil penyuluhan diperoleh sebagai berikut: 1) Peserta penyuluhan memperoleh banyak informasi terkait dengan cara mengajar yang interaktif dan tidak membosankan; 2) Meningkatkan pengetahuan dan pemahaman guru-guru dalam memberikan pembelajaran yang interaktif, sehingga pembelajaran di kelas lebih menyenangkan.
\end{abstract}

Kata kunci: Pembelajaran, Powerpoint, Ispring Presenter

\section{PENDAHULUAN}

Pendidikan pada dasarnya adalah proses membantu manusia dalam mengembangkan dirinya sehingga mampu menghadapi segala perubahan dan permasalahan dengan sikap terbuka. Pendidikan adalah hal yang harus dipenuhi untuk meningkatkan taraf hidup bangsa Indonesia agar dengan bangsa lain. Oleh karena itu sistem pendidikan nasional harus mampu memberikan jaminan pendidikan yang sama untuk seluruh indonesia untuk menghadapi perkembangan pendidikan.

Kegiatan belajar mengajar adalah suatu kondisi yang dengan sengaja diciptakan. Sadiman, dkk (1996) mengemukakan bahwa seseorang belajar karena ada yang mengajar. Mengajar dapat dipandang sebagai kegiatan atau proses yang terarah, terencana dan mengusahakan agar terjadinya proses belajar pada diri seseorang. Gurulah yang membelajarkan siswa. Guru yang mengajar dan siswa yang belajar. Perpaduan antara dua unsur manusiawi ini lahirlah interaksi edukatif yang memanfaatkan bahan sebagai mediumnya. Belajar merupakan salah satu faktor yang berperan penting dalam pembentukan perilaku seseorang. Belajar juga dapat diartikan sebagai tahapan perubahan seluruh tingkah laku individu yang relatif menetap sebagai hasil dari pengalaman dan interaksi dengan lingkungan yang melibatkan pada aktivitas siswa (proses).

Menurut Sudjana dan Rivai (2009) dalam proses belajar mengajar, ada dua aspek yang paling berpengaruh yaitu metode mengajar dan media sebagai alat bantu untuk mengajar. Media merupakan salah satu komponen komu- 
nikasi, yaitu sebagai pembawa pesan dari komunikator menuju kamunikan. Berdasarkan definisi tersebut, dapat dikatakan bahwa proses pembelajaran merupakan proses komunikasi (Criticos dalam Daryanto, 2015).

Media dapat memudahkan Guru dalam proses mengajar. Dengan adanya media siswa lebih tertarik untuk belajar. Hal ini sangat penting bagi suksesnya proses belajar dan mengajar di kelas. Dalam hal ini, media yang digunakan adalah powerpoint yang interaktif dan dengan menggunakan aplikasi ispring presenter sebagai pendukungnya. Dengan menggunakan aplikasi ini, nantinya dapat di convert menjadi video, flash, dll. Media dan aplikasi tersebut dapat dikatakan sebagai ICT (Information and Communication Technology atau Teknologi Informasi dan Komunikasi (TIK). Powerpoint adalah program komputer yang bisa digunakan untuk presentasi yang telah dikembangkan oleh Microsoft yang menjadi satu paket dengan Microsoft Office. Ispring presenter adalah salah satu tool yang mengubah file presentasi menjadi bentuk flash dan bentuk SCORM/AICC, yaitu bentuk yang biasa digunakan dalam pembelajaran dengan e-learning LMS (Learning management System). Aplikasi Ispring presenter yang terbaru dapat didownload gratis dan full versi di http://www.kuyhaa-android19.com/

Dalam berapa tahun terakhir perkembangan teknologi telekomunikasi dan jaringan komputer berjalan sangat cepat. Banyak teknologi dan aplikasi pendukung telah dikembangkan untuk mendukung dan mempermudah aktivitas manusia dan organisasi tertentu, termasuk kegiatan belajar mengajar dalam dunia pendidikan. Maka dipandang perlu untuk memberikan penyuluhan tentang media ICT tersebut pada Guru-guru SD, SMP atau SMA yang dapat mempermudah dan membantu siswa dalam memahami materi yang di ajarkan. Tetapi dalam hal ini difokuskan penyuluhan pada guru-guru SMK atau sederajat.

\section{Tujuan Penyuluhan}

Tujuan dari penyuluhan ini adalah:

1. Untuk memberikan penambahan wawasan tentang proses belajar mengajar dengan menggunakan media ICT khususnya powerpoint dan ispring presenter.

2. Untuk mempermudah Guru dalam proses belajar mengajar.

3. Untuk meningkatkan minat belajar siswa, sehingga hasil belajar siswa optimal.

\section{METODE PELAKSANAAN}

Penyuluhan ini dilaksanakan di SMK AlBadri yang terletak di Desa Arjasa, Kecamatan Kalisat, Kabupaten Jember.

\section{Materi}

Materi disampaikan dengan cara memberikan wawasan tentang pengembangan media ICT dengan menggunakan powerpoint interaktif dan aplikasi ispring presenter.

\section{Khalayak Sasaran}

Sasaran kagiatan ini adalah Guru-guru SMK Al-Badri yang membutuhkan pengembangan media ICT dengan menggunakan powerpoint interaktif dan aplikasi ispring presenter.

\section{Metode Penyampaian}

Untuk melaksanakan kegiatan tersebut digunakan dua metode yaitu:

1. Metode ceramah, dalam metode ini dijelaskan tentang kegunaan media ICT khususnya powerpoint dan ispring presenter dalam proses penyuluhan di kelas.

2. Metode tanya jawab, metode ini sangat penting bagi peserta yang mengikuti 
penyuluhan, baik disaat menerima penjelasan atau sesudah penjelasan dilakukan. Dengan menggunakan metode ini, Guru-guru mempunyai kesempatan untuk menggali pengetahuan sebanyakbanyaknya tentang media ICT dengan menggunakan powerpoint dan ispring presenter.

\section{Teknik Pengumpulan Data}

1. Observasi

a. Hal ini berguna untuk memahami konteks data dalam keseluruhan, jadi akan dapat pandangan secara menyeluruh.

b. Dengan observasi dapat memperoleh pengalaman langsung, sehingga tidak dipengaruhi oleh konsep atau pandangan sebelumnya.

2. Wawancara, hal ini berguna untuk mendapatkan informasi-informasi lebih lanjut dari peserta penyuluhan yang tidak terungkap dari observasi.

\section{Evaluasi}

Evaluasi dilakukan selama proses dan akhir penyuluhan. Yang dilakukan adalah mengidentifikasi faktor-faktor pendukung dan penghambat selama proses penyuluhan berlangsung, serta memberikan solusi permasalahan yang telah didiskusikan oleh peserta penyuluhan.

\section{HASIL DAN PEMBAHASAN \\ Powerpoint interaktif}

Microsoft Powerpoint adalah software yang telah menyediakan fasilitas untuk membantu dalam penyusunan sebuah presentasi yang efektif, professional, dan juga mudah. Microsoft Powerpointmembantu menyampaikan suatu gagasan menjadi lebih menarik dan jelas tujuannya. Berikut merupakan tampilan awal Powerpoint interaktif.

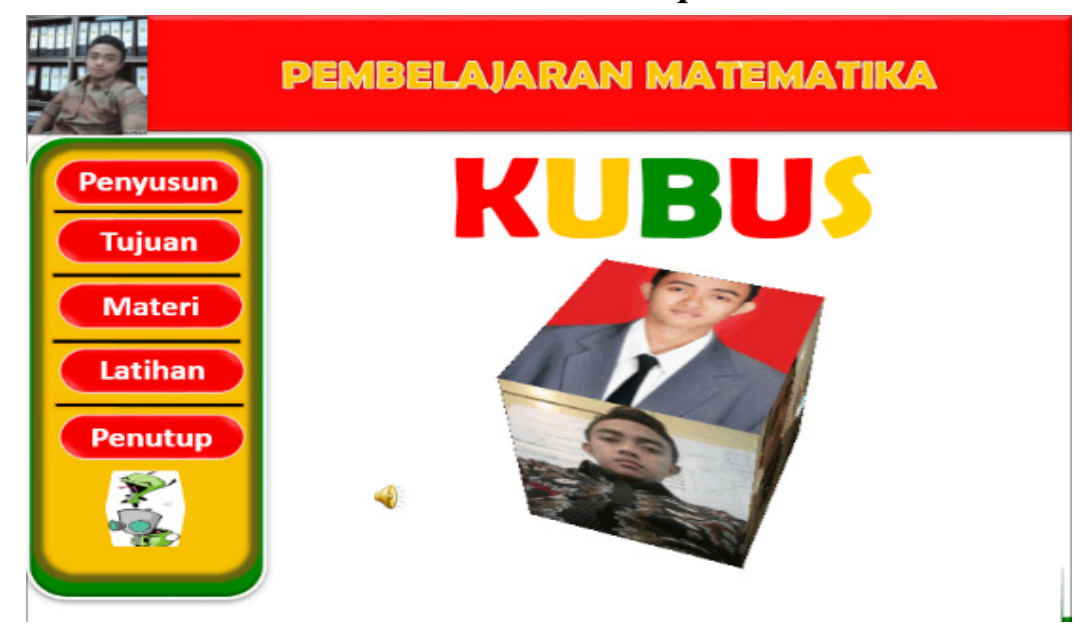

Gambar 1. Tampilan powerpoint pada slide 3

Dalam pembuatan Desain tersebut disesuaikan dengan ide masing-masing penyusun. Yang terpenting adalah membuat animasinya sehingga powerpoint tampak hidup dan lebih menarik. Dalam hal ini banyak penunjang dalam pembuatan powerpoint interaktif ini. Salah satu penunjangnya adalah Gambaryang berbentuk gif. Dengan menggunakan Gambar yang berbentuk gif tidak memerlukan lagi pengaturan animasi, karena Gambaryang berbentuk gif, otomatis sudah bergerak ketika di slide show. Dalam pembuatan Gambaryang berbentuk gif, tidak perlu bingung karena tidak perlu mempunyai kemampuan atau ilmu dalam pembuatan Gambaryang berbentuk gif. Gambaryang berbentuk gif dapat dibuat secara 
online di internet.Salah satu contoh blog yang dapat membuat Gambar yang berbentuk gif bermacam variasi adalah http://nl.bloggif.com/ cube-3d?id=6afec641e6f4c57210aaeaf6e09d cbe 0 . Berikut ini merupakan Gambar 2 slide keempat.

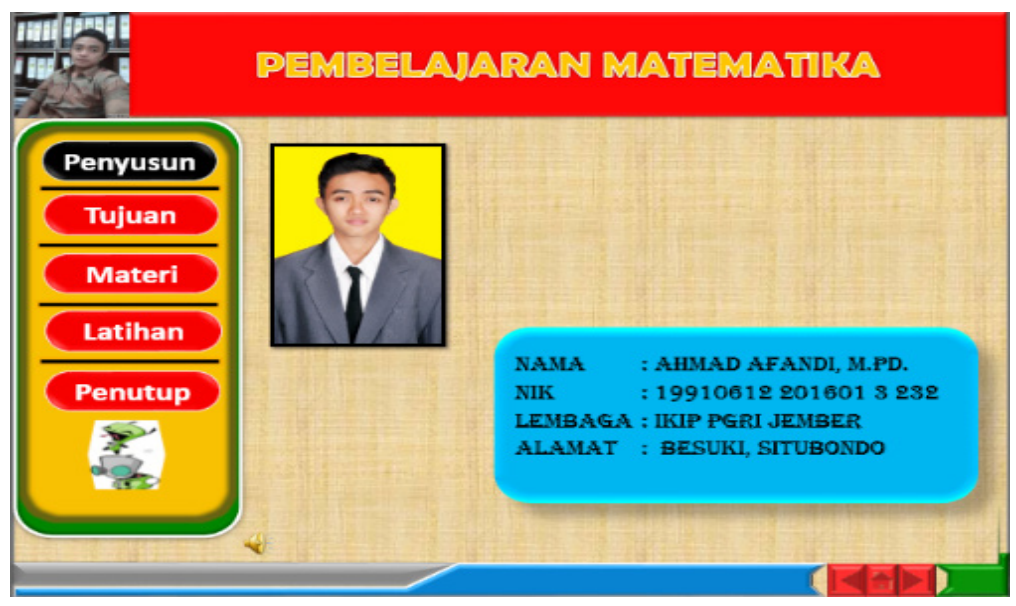

Gambar 2. Tampilan powerpoint pada slide 4

Pada Gambar 1 dan 2 diatas terdapat perbedaan warna dalam kata/tombol Penyusun. Hal ini dikarenakan pada Gambar 2 ini, menunjukkan biodata penyusun. Untuk membedakan hal tersebut, pengaturannya pada Gambar 1 slide ketiga dan ketika di klik akan berbunyi. Berikut langkah-langkahnya:

1. Klik kata/tombol penyusun

2. Pilih menu insert

3. Pilih hyperlink
4. Pilih mause clik

5. Klik hyperlink to slide yang dituju (slide ke empat)

6. Pilih play sound agar ketika di klik berbunyi dan centang highlight click

7. Pada Slide ke empat ganti warna bacroud pada kata Penyusun

Untuk lebih jelasnya, perhatikan gambar berikut ini.

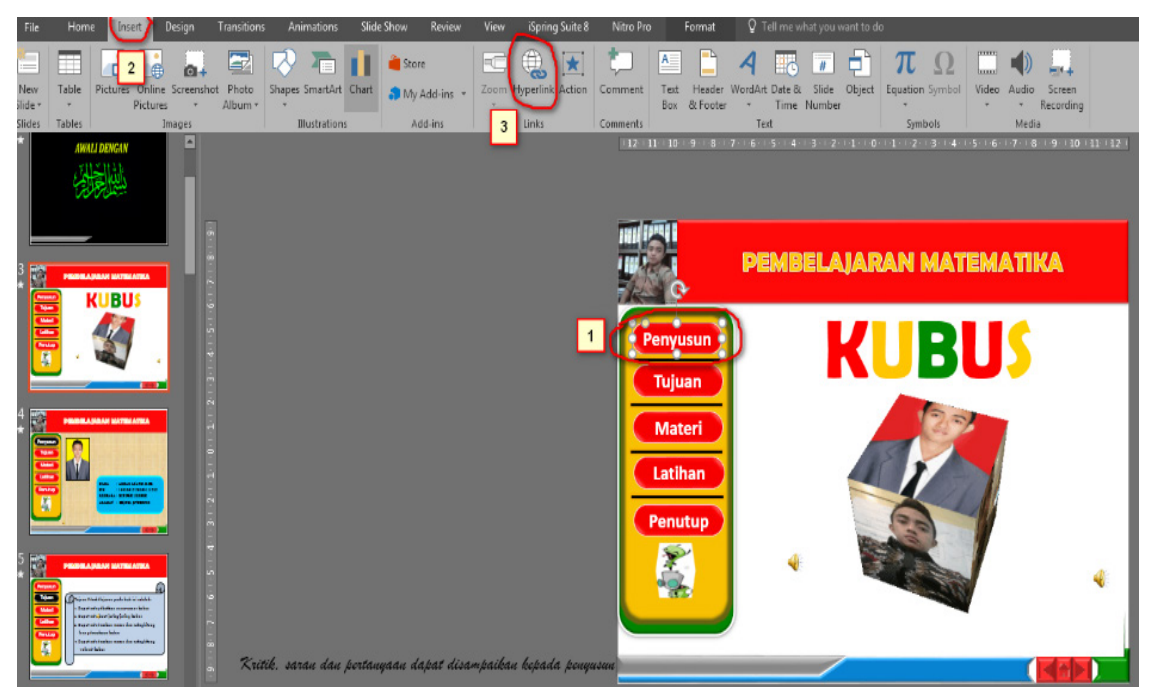

Gambar 3a. Pengaturan Tombol Penyusun (1) 


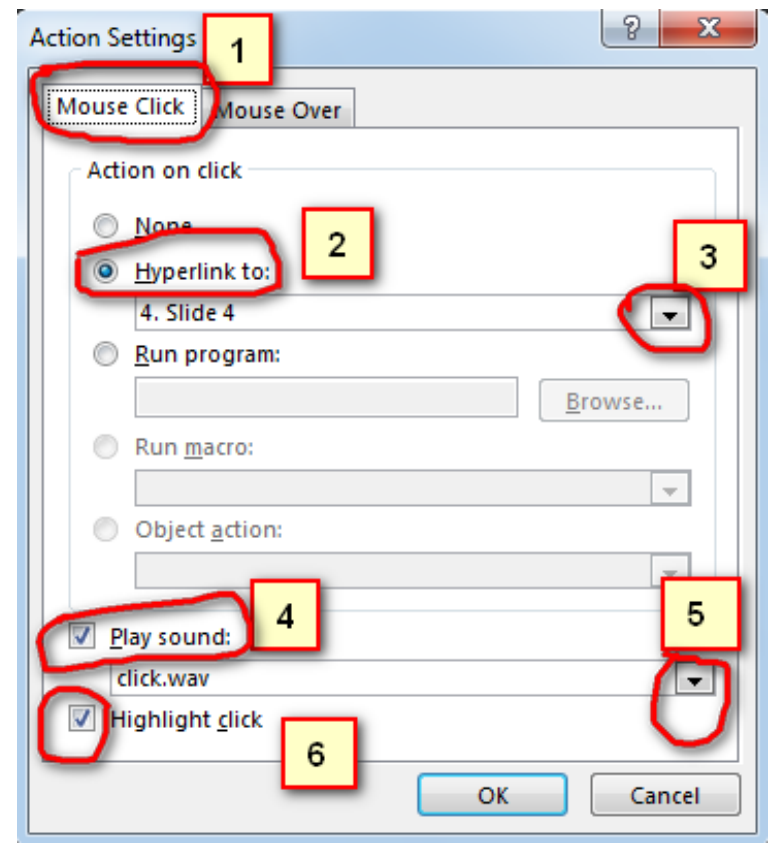

Gambar 3b. Pengaturan Tombol Penyusun (2)

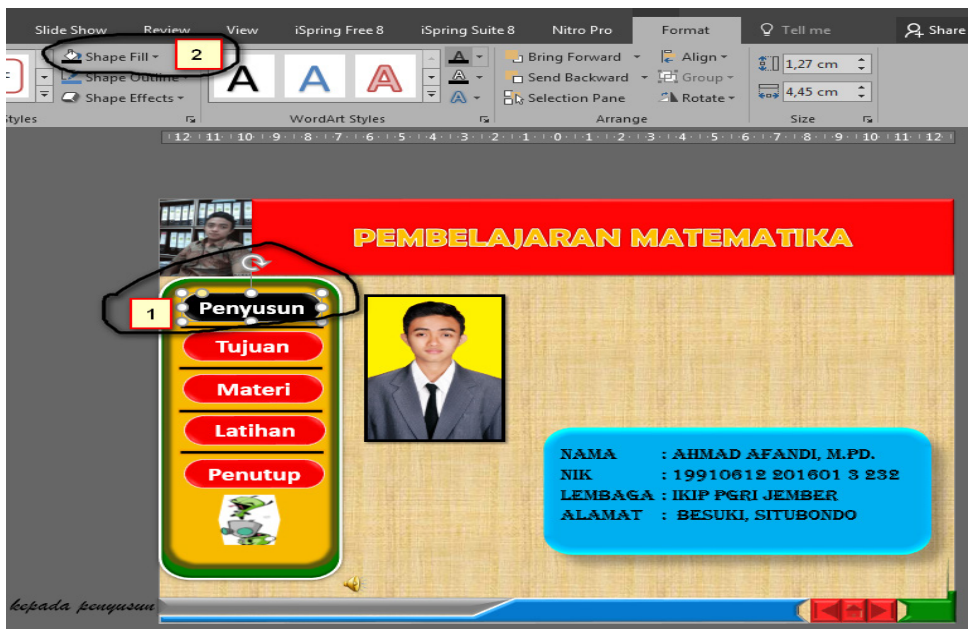

Gambar 3c. Pengaturan Tombol Penyusun (3)

Langkah tersebut dilakukan sampai pada kata/tombol Penutup. Yang membedakan hanyalah hyperlink to slidenya saja.Untuk slide berikutnya, langkah-langkah pembuatan slidenya sama dengan langkah awal yaitu hanya menggunakan animasi biasa dan hyperlink saja.

\section{Ispring presenter}

Setelah powerpoint interaktif selesai dibuat. Langkah selanjutnya adalah mempublish powerpoint interaktif tersebut ke dalam bentuk flash. Hal ini memudahkan dalam pembukaan powerpoint. Karena jika powerpoint tersebut beda versi maka, ada animasi tidak terbaca dengan sempurna. Untuk mengatasi masalah tersebut diperlukan Ispring presenter untuk mempublish menjadi flash, sehingga dapat dibuka dalam komputer/laptop manapun. Berikut langkah-langkah dalam mempublish powerpoint interaktif ke dalam bentuk flash.

1. Langkah awal sebelum mempublish adalah menginstal terlebih dahulu ispring presenternya 
2. Setelah terinstal, secara otomatis ispring presenter akan muncul pada menu powerpoint

3. Buka powerpoint yang akan di publish

4. Buka menu ispring presenternya,

5. Pilih Publish, pilih CD

6. Pada general, pilih All Slide dan Executable (EXE)
7. Pada Playback and Navigation, hilangkan semua centang pada Playback options

8. Lalu tekan kata/tombol publish dan tunggu proses publish selesai

Untuk lebih jelasnya, perhatikan Gambar dibawah ini:

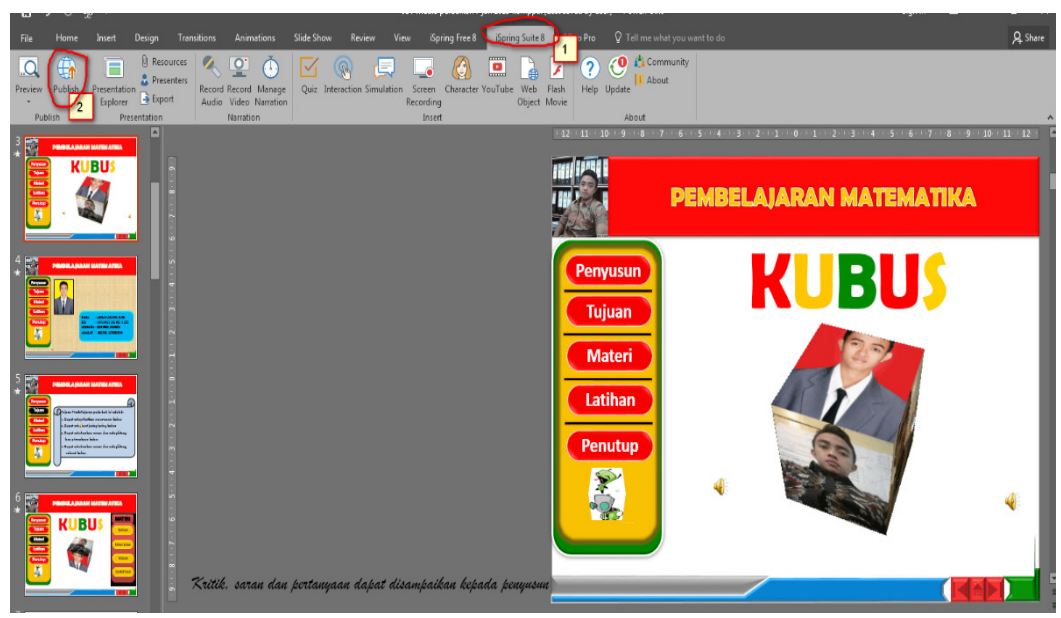

Gambar 4a. Publish dalam bentuk Flash (1)

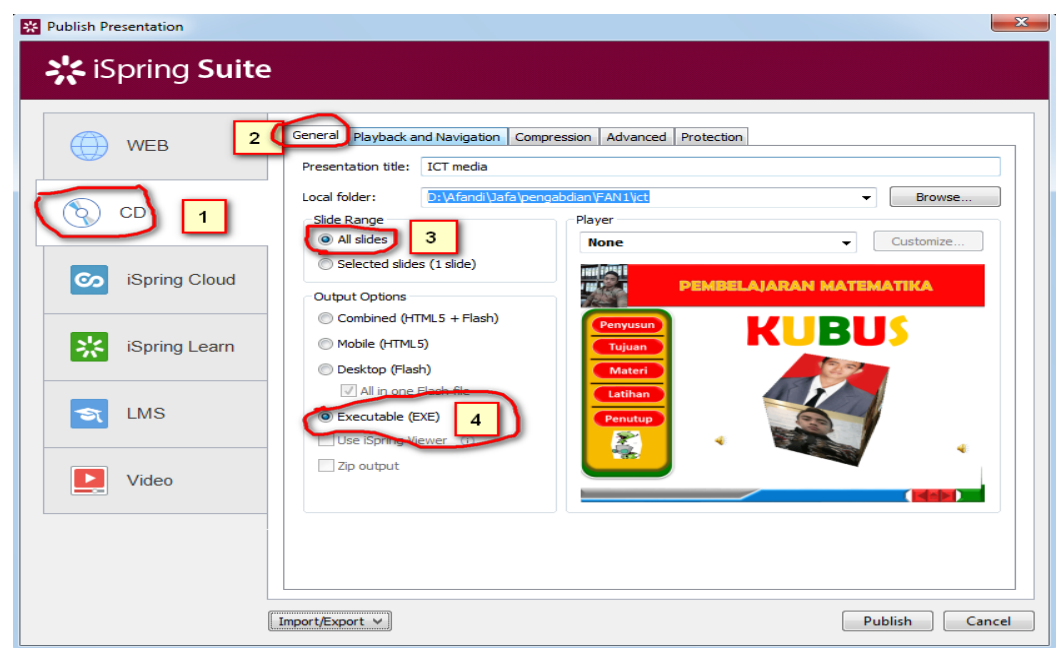

Gambar 4b. Publish dalam bentuk Flash (2) 


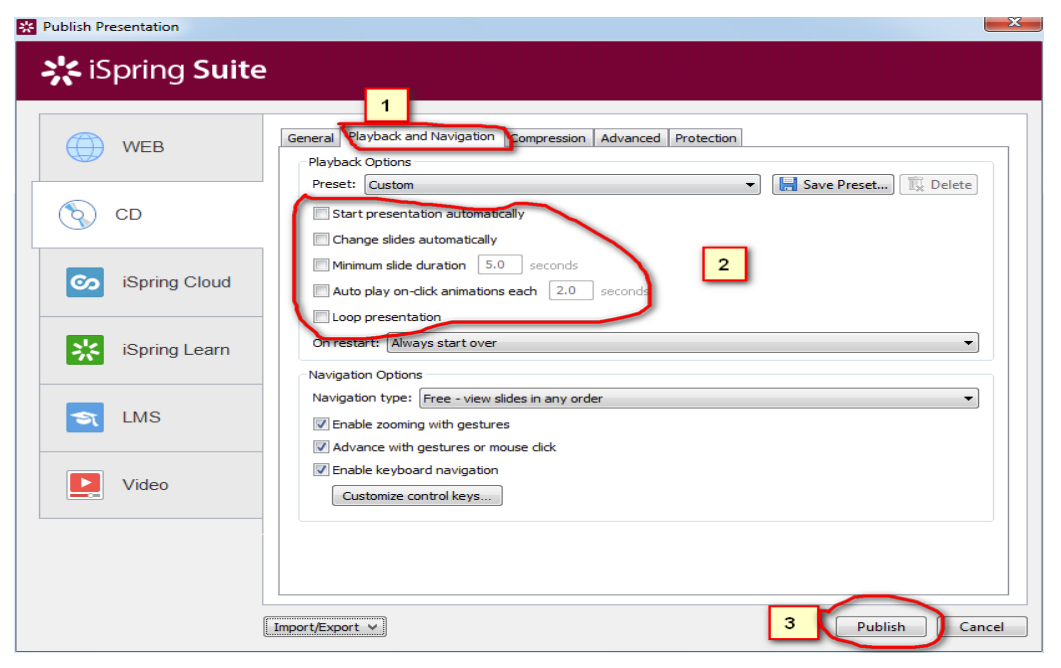

Gambar 4c. Publish dalam bentuk Flash (3)

\section{HASIL DAN PEMBAHASAN}

Hasil penyuluhan ini berupa data deskriptif yaitu data yang menggambarkan objek atau subjek sesuai dengan apa adanya. Dalam hal ini objek atau subjek yang dimaksud adalah guruguru SMK pada saat mengikuti penyuluhan dari awal sampai akhir. Berdasarkan observasi dan wawancara yang telah dilakukan, maka didapat hasil sebagai berikut:

1. Hasil Observasi

a. Meningkatkan pengetahuan dan pemahaman guru-guru dalam memberikan pembelajaran yang interaktif pada siswa dan siswinya, sehingga pembelajaran di kelas lebih menyenangkan. Hal ini perlu ditindaklanjuti dengan wawancara.

b. Sebagian besar peserta dalam mengikuti acara penyuluhan sangat antusias. Hal ini dibuktikan dengan respon peserta pada saat acara berlangsung. Banyak peserta yang bertanya dan mengomentari yang telah dijelaskan.

2. Hasil Wawancara

a. Sebagian besar guru-guru yang mengikuti penyuluhan mengaku sangat puas terhadap serangkaian kegiatan yang telah dilakukan, dikarenakan kegiatan yang dilakukan sangat bermanfaat.

b. Setelah mengikuti keseluruhan kegiatan penyuluhan, peserta banyak memperoleh informasi terkait dengan cara mengajar yang interaktif dan tidak membosankan.

\section{SIMPULAN}

Kegiatan penyuluhan ini bermanfaat bagi Guru-Guru untuk meningkatkan kemampuan dalam membuat powerpoint yang interaktif dan bisa dibuka pada komputer/laptop manapun tanpa ada rasa kekhawatiran animasi dalam powerpoint interaktif tersebut eror/tidak muncul. Yaitu dengan bantuan aplikasi ispring presenter. Hal ini juga dapat membantu Guru-Guru dalam menyampaikan materi pembalajaran pada siswa dan siswinya dengan mudah, sehingga proses belajar mengajar semakin efektif dan efesien.

\section{DAFTAR PUSTAKA}

Daryanto. (2015). Media Pembelajaran. Yogyakarta: Gava Media.

Sadiman, A.S. dkk. (1996). Media Pendidikan: Pengertian, Pengembangan, dan Peman- 
faatannya. Jakarta: PT. Raya Grafindo Sudjarat, Akhmad. (2008). Teori-teori Belajar. Persada. Jurnal Ilmu Pendidikan, (Online), http://

Sudjana, Nana \& Rivai, Ahmad. (2009). akhmadsudjarat.wordpress.com. Diakses Media Pengajaran. Bandung: Sinar Baru Algensindo. 07 November 2016. 